BOHIER, Caroline Novaes; SILVEIRA, Luana da. A necropolítica sobre gestação e maternidade: o posicionamento ético-político do(a) Psicólogo(a) no Sistema Único de Saúde (SUS).

\title{
A necropolítica sobre gestação e maternidade: o posicionamento ético- político do(a) Psicólogo(a) no Sistema Único de Saúde (SUS)
}

The necropolitics on gestation and maternity: the ethical-political positioning of the Psychologist in the Unified Health System (SUS)

\section{Luana da Silveira}

\section{Orientadora}

luanadasilveira76@gmail.com

Doutora em Psicologia Social - UERJ. Mestre e especialista em Saúde ColetivaISC/ UFBA. Doutora em Psicologia Social - UERJ. Graduada em Psicologia- UNISC.

\section{Caroline Novaes Bohier Autora \\ carolnbohier@gmail.com}

Graduanda em Psicologia - UFF - Campos dos Goytacazes.

\section{Resumo}

A necropolítica afeta as mulheres, principalmente negras e pobres. O presente trabalho discute dois processos que evidenciam essa política e o posicionamento ético-político do psicólogo/a em cada um: o (não) direito de abortar; e a idealização da maternidade via análise do caso de Amanda, em que sou acompanhante terapêutica (AT).

Palavras-chave: maternidade; parto; gestação; aborto; Psicólogo/a.

\section{Abstract}

The necropoly affects women, especially black and poor. This paper discusses two processes that highlight this policy and the ethical-political position of the psychologist in each: the (not) right to abortion; obstetric violence; and the idealization of motherhood through analysis of the Amanda case, in which I am a therapeutic companion (AT).

Key-words: maternity; childbirth; gestation; abortion; Psychologist. 
BOHIER, Caroline Novaes; SILVEIRA, Luana da. A necropolítica sobre gestação e maternidade: o posicionamento ético-político do(a) Psicólogo(a) no Sistema Único de Saúde (SUS).

\section{Introdução}

A partir do conceito de Foucault (2014) de biopolítica, ou seja, do fazer viver, problematiza-se por meio de Membe (2003) a desconsideração da periferia. No grupo de vulnerabilizados trata-se de uma necropolítica, do fazer morrer. $\mathrm{O}$ presente trabalho pretende analisar dois processos (1) a gestação, discutindo o direito ao aborto (2) e a maternidade idealizada. Todos envolvem o tornar-se mãe onde o patriarcalismo impõe sobre a mulher comportamentos diversos.

Na teoria do filósofo francês Foucault (2014), a sociedade está submetida a um biopoder que produz docilidade-utilidade nos sujeitos, gerando corpos dóceis. O corpo dócil é aquele "que pode ser submetido, que pode ser utilizado, que pode ser transformado e aperfeiçoado" (FOUCAULT, 2014, p.134). Sendo assim, o que está em jogo é gerar sujeitos submissos politicamente e úteis produtivamente, ou seja, como uma classe operária domável, então é necessário um corpo saudável. A medicina, atravessada pela lógica, é o saber que produz vida a qualquer custo e tenta livrar o corpo da morte.

Posteriormente, na segunda metade do século XX, o capitalismo entra em colapso e passa a precisar de menos trabalhadores, devido ao aumento das máquinas e da decomposição orgânica do capital: "a ação é a de expulsar massas humanas, jogar pessoas no desemprego estrutural, empurrá-las para as periferias da cidade, para as prisões ou simplesmente aniquilálas por meio das forças policiais, oficiais ou não (expulsão)" (HILÁRIO, 2016, p.202). Dessa forma, os sujeitos que estão marginalizados socialmente se tornaram inúteis, dispensáveis.

Não se tratando de corpos úteis produtivamente, consequentemente não se tratam de corpos que a medicina vai se dedicar a manter vivo. Então, para o grupo vulnerabilizado, não se trata de uma política voltada para a produzir vida, mas sim um deixar morrer. Sendo assim, Achille Mbembe (2003) atualiza a crítica foucaultiana afirmando que esses sujeitos vulnerabilizados estão, portanto, sob uma necropolítica (HILÁRIO, 2016).

As mulheres fazem parte do conjunto dos marginalizados devido à estrutura patriarcal, uma estrutura social hierárquica que coloca o homem como superior à mulher. Tratando-se de uma escrita que aborda três processos transversais à maternidade, é essencial considerar a posição que a mulher ocupa histórico-socialmente e a lógica machista que atravessa a todos, sendo então, todos possíveis agentes de violência.

Para pensar a estrutura social opressora, é necessário ir além da questão de gênero, sendo indispensável considerar os atravessamentos de raça, visto que mulheres negras, pardas ou 
BOHIER, Caroline Novaes; SILVEIRA, Luana da. A necropolítica sobre gestação e maternidade: o posicionamento ético-político do(a) Psicólogo(a) no Sistema Único de Saúde (SUS).

indígenas apresentam maiores dificuldades de acesso à saúde. Além disso, é importante considerar a classe social, pois "tanto o racismo quanto o patriarcado são estruturantes e estão interseccionalizados com a organização econômica, logo, não podem estar descolados da classe social" (PASSOS, 2018, p.12).

Além da lógica machista, racista e classista, a realidade vivida pelas mulheres que desejam abortar no Brasil é norteada pelos atravessamentos da moral religiosa-cristã. Tal conjuntura permite questionar quais são as mulheres que conseguem escolher pela interrupção da gravidez, visto que o aborto continua a ser praticado no Brasil, mas em muitos casos de forma perigosa e gerando até mortes, esse é o caso de Deuseli, história contada no documentário "À margem do corpo" (DINIZ, 2006). Nesse cenário, é essencial uma problematização do Decreto de Lei $2848 / 40^{1}$ do Código Penal Brasileiro, entendendo qual o posicionamento do profissional de psicologia em tal contexto.

No período pós-nascimento, a mulher ainda se depara com o ideal de mãe, ou seja, a imposição de um perfil materno que não se enquadra para todas as mulheres. Para melhor compreensão desse ideal, será apresentado o caso de Amanda, de quem sou acompanhante terapêutica (AT) via grupo de pesquisa-intervenção "Saúde Mental e Justiça", do curso de Psicologia, da Universidade Federal Fluminense (UFF), Campos dos Goytacazes, além do o AT como um método de intervenção possível nesse processo.

\section{Quem pode escolher abortar?: saúde à margem do corpo negro e pobre}

De acordo com o Decreto de Lei 2848/40 (1940) do Código Penal Brasileiro, no Art. 128, o aborto é um crime contra a vida, visto que se localiza no título: "Dos crimes contra a pessoa". Entretanto, é evidente que diversas mulheres praticam a interrupção da gravidez apesar de todas as implicações legais, sociais e afetivas.

\footnotetext{
1 "CAPÍTULO I

DOS CRIMES CONTRA A VIDA: [...]
}

Parágrafo único - A pena é duplicada: [...]

Art. 124 - Provocar aborto em si mesma ou consentir que outrem Iho provoque: (Vide ADPF 54) Ver tópico (2827 documentos)

Pena - detenção, de um a três anos.

Aborto provocado por terceiro

Art. 125 - Provocar aborto, sem o consentimento da gestante: Ver tópico (4428 documentos)

Pena - reclusão, de três a dez anos.

Art. 126 - Provocar aborto com o consentimento da gestante: (Vide ADPF 54)"

DIGNIDADE RE-VISTA | ISSN2525-698X| 2020 | V. V | N. 10 | Um olhar para a Amazônia: riquezas e

diversidades. | Sessão livre. Pastoral Universitária Anchieta PUC-RIO. 
BOHIER, Caroline Novaes; SILVEIRA, Luana da. A necropolítica sobre gestação e maternidade: o posicionamento ético-político do(a) Psicólogo(a) no Sistema Único de Saúde (SUS).

De acordo com a Pesquisa Nacional do Aborto, uma a cada cinco mulheres de até 40 anos vão fazer um aborto durante a vida, sendo esta uma das principais causas de mortalidade de mulheres em idade fértil (DINIZ, MADEIROS \& MADEIRO, 2017). Para melhor análise desse dado, é necessário olhar sobre as mulheres de classes populares, principalmente negras, que muitas vezes desejam abortar, mas encontram dificuldades. Em alguns casos, a falta de recursos financeiros impede o processo, enquanto outras fazem um procedimento altamente perigoso e de baixa qualidade, arriscando suas vidas. De acordo com o Conselho Federal de Enfermagem (2018), uma mulher morre a cada dois dias devido a aborto inseguro.

Nesse cenário, é necessário abordar a estrutura patriarcal já que o ideal da maternidade não se separa da lógica machista, pois se insere em um funcionamento familiar em que os homens trabalham fora e as mulheres cuidam dos filhos, inclusive mulheres negras cuidam dos filhos de mulheres brancas. Nesse movimento, a maternidade torna-se o destino da mulher (NOVELINO, 1988; BEAUVOIR, 1949), sendo que nem todas alimentam o desejo de gerar um filho. Quando se engravida e não há desejo de parir, apenas as mulheres mais privilegiadas alcançam algo que deveria se tratar de um direito, o que coloca as mulheres negras e pobres em uma intensa necropolítica, já que a maioria é mãe solo e trabalhadora.

Quanto à estrutura cristã, a moral religiosa dispõe da concepção de que a vida inicia a partir da junção do óvulo com o espermatozóide. O cristianismo defende que fetos já podem ser considerados seres vivos. Logo, assume a postura de que abortar é pecado, porque apenas quem pode tirar a vida é Deus: "Não matarás" (Êxodo 20:13). De acordo com o censo feito pelo Instituto Brasileiro de Geografia e Estatística (IBGE), 86,8\% da população do Brasil se afirmou como cristã em 2017. Sendo assim, a maioria dos brasileiros também assume tal perspectiva de vida, onde os profissionais do Sistema Único de Saúde também se incluem e, em muitos casos, são diretamente influenciados pela lógica moral. Como podemos ver no caso abaixo.

No documentário "À margem do corpo" (DINIZ, 2006), apresenta-se a história de cunho antropológico, de uma muher negra e pobre, Deuseli Vanines. A autora parte de um processo judicial que marca a narrativa, o estupro vivido por ela com 19 anos, comprovado em processo judicial, em que houve condenação do homem.

Após a condenação, Deuseli solicita, por meio do Judiciário, o seu direito de fazer a interrupção de gravidez gerada do estupro. Posterior à condenação do estuprador, consegue-se a autorização judicial. A partir de então, a Promotora de Justiça de seu território, Márcia de Almeida, passa a procurar diversos hospitais com estrutura, mas não encontra no pequeno 
BOHIER, Caroline Novaes; SILVEIRA, Luana da. A necropolítica sobre gestação e maternidade: o posicionamento ético-político do(a) Psicólogo(a) no Sistema Único de Saúde (SUS).

povoado do interior de Goiás que Deuseli morava, até que um dia decide procurar em Anápolis, no Hospital Municipal (ALMEIDA, 2012).

A Promotora conversa, primeiramente, com o gestor do hospital, que afirma que se algum médico escolher fazer, que é lícito. Ela decide, então, conversar com todos os médicos, de um por um, até que um se sensibiliza com a tortura que Deuseli sofreu. Apesar de dizer que faria, o médico passa a pedir diversos documentos afirmando que só praticaria o aborto após recebêlos (ALMEIDA, 2012). Enquanto isso, afirmam à Deuseli que o remédio ainda não chegou, entregando apenas um medicamento qualquer para que ela desistisse, até o dia em que a liberaram ainda grávida.

Ainda durante o processo de entrevistas dos médicos, Márcia de Almeida conta que ouve de um dos médicos: "Se ela chegar aqui em processo de abortamento a gente faz a curetagem, que é o que acontece com todas as mulheres que chegam aqui. Todas chegam com o processo de abortamento já iniciado em casa" (ALMEIDA, 2012).

A afirmação do médico é analisadora da realidade do aborto no Brasil, visto que reafirma que as mulheres abortam, mesmo com existência de uma lei que proíba, sendo que, ao mesmo tempo, está diante de uma mulher negra e pobre que não tem dinheiro para fazer um aborto da mesma forma que essas mulheres que chegam no hospital, visto que "as mulheres negras e pobres são aquelas que estão (pré) destinadas a morrer por conta dos abortos chamados clandestinos" (CURI \& GAMA, 2018, p.200).

Se no Brasil as mulheres abortam apesar de todas as implicações legais, sociais e afetivas e principalmente aquelas que são pobres e negras estão fadadas a mortes causadas por abortos clandestinos, torna-se essencial questionar a utilidade do Decreto de Lei que impede o aborto no Brasil, visto que a lei não tem utilidade na execução. Os abortos acontecem e a lei apenas impede a preocupação com a saúde da mulher.

Débora Diniz, diretora do documentário “À margem do corpo" (2006), que tem um trabalho de referência em bioética, direitos das mulheres e direitos humanos, afirma que "a ilegalidade traz consequências para a saúde das mulheres, que não coíbe a prática e perpetua a desigualdade social” (DINIZ, 2007). Em países proibidos ou parcialmente proibidos, um de cada quatro abortos é seguro, já em países onde é legalizado, nove de cada dez abortos são seguros (ONU, 2017). Dessa forma, fica evidente que a ilegalidade do aborto apenas impede uma preocupação com a saúde das mulheres negras e pobres.

Quanto ao papel político do profissional em saúde, o Código de Ética Profissional do Psicólogo (2005), segundo seus Princípios Fundamentais, afirma: “I. O psicólogo baseará o seu 
BOHIER, Caroline Novaes; SILVEIRA, Luana da. A necropolítica sobre gestação e maternidade: o posicionamento ético-político do(a) Psicólogo(a) no Sistema Único de Saúde (SUS).

trabalho no respeito e na promoção da liberdade, da dignidade, da igualdade e da integridade do ser humano, apoiado nos valores que embasam a Declaração Universal dos Direitos Humanos" (Código de Ética Profissional do Psicólogo, 2005, p.7).

Dessa forma, é papel do/a psicólogo/a se estabelecer com outros saberes horizontalmente de forma a construir uma saúde possível, que respeite as escolhas individuais. Em concordância, o Conselho Federal de Psicologia (CFP) se coloca a favor da descriminalização e legalização do aborto, afirmando que a defesa dos direitos sexuais e reprodutivos das mulheres é a defesa de seus direitos humanos (CFP, 2018).

Quanto à posição ética, sempre deve ser pautada na bioética, problematizando o caso a caso e baseado no Código de Ética do Profissional de Psicologia. No quadro do aborto, é necessário que, ao receber para a curetagem já citada, o profissional faça um trabalho humanizado, respeitoso e sem julgamentos morais. De acordo com o artigo $2^{\circ}$ do Código de Ética (2005):

Ao psicólogo é vedado:

a) Praticar ou ser conivente com quaisquer atos que caracterizem negligência, discriminação, exploração, violência, crueldade ou opressão;

b) Induzir a convicções políticas, filosóficas, morais, ideológicas, religiosas, de orientação sexual ou a qualquer tipo de preconceito, quando do exercício de suas funções profissionais. (p.9)

Sendo assim, diante de todas as condições de aborto praticadas pelo SUS, é necessário reafirmar que é um compromisso ético-político dos psicólogos/as e estudantes de Psicologia de lutar "não só pela descriminalização do aborto, mas também pela sua legalização e pela garantia de acesso das mulheres ao sistema público de saúde" (CURI \& GAMA, 2018, p.201). Da mesma forma que é necessário a problematização acerca do aborto, se faz necessário repensar a maneira e as condições em que se fazem os partos no Brasil, como veremos a seguir.

\section{Maternidade e loucura: ressonâncias do AT}

Da mesma forma que as mulheres sofrem violência quando escolhem fazer um aborto, sofrem com muitas imposições quando se tornam mães. Uma dessas ordens é o papel social destinado à mulher, que continua sendo na família, sendo o lar o local que ela encontra a realização pessoal. Sendo assim, a maternidade ainda se localiza no centro do "ser mulher", onde ainda existe um ideário cultural da mulher como possuidora de um "instinto materno" (NOVELINA, 1988 \& BEAUVOIR, 1949). Refere-se, então, a uma interiorização de um 
BOHIER, Caroline Novaes; SILVEIRA, Luana da. A necropolítica sobre gestação e maternidade: o posicionamento ético-político do(a) Psicólogo(a) no Sistema Único de Saúde (SUS).

pensamento universal sobre o que é ser mãe, que se traduz a "branca, jovem, pertencente às camadas econômicas média e alta, insegura quanto à criação dos filhos e, sem dúvida, inserida numa família legitimamente construída" (NOVALINA, 1988, p.24). Entretanto, é importante lembrar que nem todas as mulheres se encaixam nesse perfil de maternidade idealizada. Quando isso ocorre, a mãe pode ser colocada como incapaz ou como se tivesse fracassado em seu papel.

Nesse contexto, o profissional de psicologia é, muitas vezes, cooperador para a construção desse estereótipo de mãe, por meio de aconselhamentos, afirmando que a mulher deve ser de determinada forma para ser considerada uma boa mãe (NOVALINA, 1988). Entretanto, parte da ética do/a psicólogo/a é o respeito às individualidades de cada sujeito. No caso da maternidade, é importante que o profissional esteja atento a tais especificidades da pessoa, construindo em conjunto uma forma singular de maternidade.

Dentro dos moldes impostos socialmente certamente não se encaixa ser usuária dos serviços de saúde mental ou ter algum diagnóstico de sofrimento psíquico. Esse é o caso de Amanda $^{2}$, de quem sou Acompanhante Terapêutica (AT) via grupo de pesquisa-intervenção "Saúde Mental e Justiça"3 vinculado à instituição Universidade Federal Fluminense de Campos dos Goytacazes e encaminhado pela Rede de Atenção Psicossocial (RAPS).

O Acompanhamento Terapêutico (AT) é um dispositivo clínico-político complexo de desinstitucionalização que permite aproximação com aqueles usuários pouco acessados pelas formas tradicionais de tratamento (PALOMBINI, 2006). Além disso, o AT “propõe a clínica a partir do "manejo das relações vinculares" ao acreditar que nestas os efeitos terapêuticos são produzidos" (CUSTÓDIO, 2017, p.27). Sendo assim, não se concretiza em apenas um, mas aparece nas relações construídas pelo acompanhado (CUSTÓDIO, 2017).

Ademais, em nosso grupo de pesquisa-intervenção "Saúde mental e justiça", o modelo adotado atualmente é de fazer o acompanhamento em duplas ou grupo. Tal formato permite um

\footnotetext{
${ }^{2}$ Nome fictício, assim como das outras pessoas dessa pesquisa-intervenção

3 "Foi criado o projeto de extensão em desinstitucionalização, cujo o objetivo é produzir novas tecnologias e dispositivos de cuidado através do acompanhamento terapêutico (AT). Trata-se do acompanhamento de usuários de saúde mental, com histórico de sucessivas internações psiquiátricas para o processo de desinstitucionalização, através da atenção domiciliar e da articulação com os pontos de atenção da rede. [...] Anterior e concomitante a esse projeto, desde setembro de 2014, o grupo de saúde mental e justiça tem se dedicado à dimensão jurídico-política (AMARANTE, 2011). Esse grupo tem problematizado os atravessamentos sobre a produção do "louco perigoso", considerando o controle e dominação exercidos sobre este sujeito, a partir do saber/poder psiquiátrico e jurídico na execução de sanções como: medida de segurança, internação compulsória e interdição/ curatela judicial” (BRITO \& SILVEIRA, 2018, p.137-8).
}

DIGNIDADE RE-VISTA | ISSN2525-698X| 2020 | V. V | N. 10 | Um olhar para a Amazônia: riquezas e diversidades. | Sessão livre. Pastoral Universitária Anchieta PUC-RIO. 
BOHIER, Caroline Novaes; SILVEIRA, Luana da. A necropolítica sobre gestação e maternidade: o posicionamento ético-político do(a) Psicólogo(a) no Sistema Único de Saúde (SUS).

compartilhamento das angústias e aflições que fazem parte do processo de intervenção (ALMEIDA \& FREITAS, 2007).

No primeiro momento, quando o grupo recebe o caso, a demanda inicial surge nos impasses da relação de Amanda e Solange - mãe e filha. O maior desafio de construção da desinstitucionalização ${ }^{4}$ com Amanda é a dificuldade que sua mãe apresenta de recebê-la em casa. A fala que Solange sempre apresenta aos técnicos é de que Amanda é caso grave, então tem que ficar guardadinha para que assim possa cuidar de Lucas - filho de Amanda. Logo, os primeiros desafios encontrados por nós enquanto ATs são as questões atravessadas por uma maternidade ideal que Solange espera de Amanda, pensamento totalmente atravessado pelo estereótipo do louco violento.

Em nosso primeiro encontro com Amanda, ela está acolhida no serviço de atendimento às urgências em saúde mental e a porta de entrada da atenção à crise. Os trabalhadores nos atentam que esse é o movimento vivenciado por ela: (1) acolhimento no serviço de saúde mental em regime ambulatorial (2) ou no serviço de porta de entrada no qual a conhecemos (3) ou internação no hospital psiquiátrico da cidade. Esse período de acolhimento ou internação é seguido de um breve retorno para a casa e sucedido de um novo retorno a um desses três destinos.

Devido ao serviço que está acolhida ser um espaço apenas temporário de porta de entrada e à impossibilidade de retorno para sua casa, visto que sua mãe nega recebê-la, Amanda é encaminhada para uma internação no hospital psiquiátrico da cidade. No primeiro encontro com ela no hospital, o assunto sobre maternidade surge. Ao entrarmos, ela se aproxima me dando um abraço forte e dizendo em meu ouvido "eu nunca quis perder meu filho". Nesse momento permanecemos abraçadas por todo o resto do tempo da visita, cerca de trinta minutos. Ora ela coloca seu peso sobre mim à procura de consolo e ora me coloca em seu ombro e repete "você é Amanda agora", ato que evidencia uma vivência exclusivamente feminina entre nós.

Tal encontro terapêutico com Amanda evidencia a importância de uma intervenção em dupla, visto que, enquanto estávamos abraçadas, minha dupla exerceu a função de holding, ou seja, de não estar ativo, mas estar presente (ALMEIDA \& FREITAS, 2007). Além disso, coloca em análise a implicação do intervencionista. Um encontro tão potente e, em certo nível, íntimo

\footnotetext{
${ }^{4}$ A desinstitucionalização trata-se do "alargamento do campo possível de tratamento e, desse modo, dar visibilidade" ao sujeito com sofrimento psíquico, possibilitando uma nova organização subjetiva e social "através de dispositivos e estratégias terapêuticas descentradas de seu antigo aspecto assistencial” (ALMEIDA \& FREITAS, 2007)
} 
BOHIER, Caroline Novaes; SILVEIRA, Luana da. A necropolítica sobre gestação e maternidade: o posicionamento ético-político do(a) Psicólogo(a) no Sistema Único de Saúde (SUS).

entre nós, recusa uma posição neutra por parte do pesquisador e procura romper com a ideia objetivista de sujeito que conhece e objeto a ser conhecido. No momento em que estamos abraçadas, não existe "sujeito e objeto, mas processos de subjetivação e de objetivação, criação de planos que ao mesmo tempo criam sujeitos/objetos, que se revezam" (PASSOS \& BARROS, 2000, s/p.). Logo, pesquisador e pesquisado se constituem no mesmo processo, concomitantemente (PASSOS \& BARROS, 2000).

Entretanto, paralelo ao nítido desejo de Amanda de estar mais próxima de seu filho, Solange reafirma que sua filha não tem capacidade de cuidar de Lucas. É evidente, assim, o desafio de desconstrução de uma maternidade ideal na mãe, que espera que a filha crie o neto assim como ela criaria. Muitas vezes questiona-se sobre a condição de avó estar acima da condição de mãe, na dificuldade de entender que ela também se sente mãe de Lucas. Não é simples entender a forma como Solange funciona, que na maior parte do tempo apenas abandona sua filha, apresentando um funcionamento de manicômio mental: "prática tutelar e encarceradora" (CUSTÓDIO, 2017, p.72) com a diferença. É importante ressaltar ainda a sobrecarga de cuidado que Solange vivencia no ambiente familiar, sendo a ausência dos homens um analisador da constituição de muitas famílias de pessoas com sofrimento psíquico.

A prática do AT é uma intervenção em concordância com a Reforma Psiquiátrica e a Luta Antimanicomial. O movimento da luta antimanicomial é parte das lutas a favor dos direitos dos usuários e familiares a uma atenção digna a serviços públicos de saúde com qualidade, que visam a mudança do imaginário social sobre a loucura (BARBOSA, COSTA \& MORENO, 2012). Além disso, é uma luta pela diversidade de existências:

O manicômio é expressão de uma estrutura, presente nos diversos mecanismos de opressão desse tipo de sociedade. A opressão nas fábricas, nas instituições de adolescentes, nos cárceres, a discriminação contra negros, homossexuais, índios, mulheres. Lutar pelos direitos de cidadania dos doentes mentais significa incorporar-se à luta de todos os trabalhadores por seus direitos mínimos à saúde, justiça e melhores condições de vida (Manifesto de Bauru, 1987, s/p.).

Além disso, tratando-se de maternidade, o profissional de psicologia ocupa um lugar especial, visto que nos últimos tempos houve uma psicologização da maternidade, onde o/a psicólogo/a passa a ser um profissional de lugar importante na normatização da maternidade, visto que "aos especialistas da psicologia vem sendo atribuído o poder de definir e fixar os contornos apropriados à vivência afetiva" (NOVELINA, 1988, p.22).

Nesse contexto, o papel do militante da luta antimanicomial e do AT é a defesa da diversidade. Por isso, é necessário sempre trazer problematizações sobre o assunto com Solange 
BOHIER, Caroline Novaes; SILVEIRA, Luana da. A necropolítica sobre gestação e maternidade: o posicionamento ético-político do(a) Psicólogo(a) no Sistema Único de Saúde (SUS).

para que, com tempo e paciência, seja trabalhado que Amanda pode, com sua singularidade, habitar a cidade e conseguir ser mãe. Entende-se que esse é um trabalho árduo e demorado, já que faz parte da realidade complexa de uma família com uma realidade socio-história. É nesse contexto que o AT se insere, visto que tenta entender a vivência singular de cada um dos três membros da família, auxiliando no manejo das relações e no que mais for possível. Ainda existem muitos mistérios desconhecidos na família de Solange, Amanda e Lucas. Mergulharemos neles.

\section{Conclusão}

Como visto, é possível afirmar que as mulheres são parte do grupo atingido pela necropolítica devido à estrutura patriarcal, intensificada nos corpos das mulheres negras e de classe mais baixa, o que fica perceptível nos três momentos apresentados no decorrer do texto. Além disso, apresenta-se o posicionamento ético-político do/a psicólogo/a do Sistema Único de Saúde e o AT como possibilidade de acompanhamento desses processos.

No primeiro momento, as mulheres enfrentam dificuldades para interromper uma gravidez devido a criminalização do aborto. As mulheres com um certo poder aquisitivo pagam para fazer o procedimento de forma clandestina. Já as mulheres pobres, normalmente negras, não conseguem o mesmo acesso, passando por procedimentos altamente arriscados. Além disso, é para essas mulheres vulnerabilidades que se impõe um ideal de mãe baseado no perfil do qual não conseguem se encaixar, como é o caso de Amanda.

O papel do profissional de psicologia (em formação ou não) é valorizar o sofrimento psíquico causado pela opressão social e lutar pelo fim dela. É o posicionamento da defesa de um tratamento digno para pessoas que abortam e, para um futuro, a descriminalização e legalização do mesmo; além do posicionamento da defesa de uma pluralidade de possibilidades de construir uma maternidade, como também construir outras possibilidades terapêuticas, como o AT. Este que está para além da clínica tradicional e se apresenta como uma possibilidade de intervenção na realidade social de Amanda pela potência de transformar forças individuais e coletivas/internas e externas que interferem/definem sua condição de mãe. 


\section{Referências bibliográficas}

À margem do corpo. Debora Diniz/Fabiana Paranhos. Goiás: Debora Diniz, 2012. (43min), son., color. Youtube. Disponível em: $<$ https://www.youtube.com/watch?v=4PoxtwM8nik\&t=1167s>. Acesso em: 28 de nov. 2018.

ALMEIDA, Lorena \& FREITAS, Lygia. A Formação de Díades no Trato com a Loucura: Acompanhando o acompanhante. In: SILVA, Marcus Vinicius (Ed.). A Clínica Psicossocial das Psicoses. Salvador: Intesaextensa, 2007 p.141-45.

AZEVEDO, Reinaldo. O IBGE e a religião - Cristãos são 86,8\% do Brasil; católicos caem para 64,6\%; evangélicos já são 22,2\%. Disponível em: $<$ https://veja.abril.com.br/blog/reinaldo/o-ibge-e-a-religiao-cristaos-sao-86-8-do-brasilcatolicos-caem-para-64-6-evangelicos-ja-sao-22-2/>. Acesso em: 28 nov. 2018.

BARBOSA, Guilherme; COSTA, Tatiana \& MORENO, Vânia. Movimento da luta antimanicomial: trajetória, avanços e desafios. Cad. Bras. Saúde Mental. v.4, n.8, p.45-50, 2012.

BEAUVOIR, Simone. História. Sérgio Milliet. In: BEAUVOIR, Simone. O segundo sexo: fatos e mitos. Rio de Janeiro: Editora Nova Fronteira Participações S.A., p. 95-158, 2016.

BENEVIDES, Regina. A Psicologia e o Sistema Único de Saúde: quais interfaces? Psicologia \& Sociedade. v.17, n.2, p.21-5, 2005.

Bíblia. Português. Bíblia do adolescente: aplicação pessoal. Marta Doreto de Andrade. Brasil: CPAD, 2008. 1604 f. Vol 1.

BRASIL. Decreto ${ }^{\circ}$ 2.848, de 7 de dezembro de 1940. Dos crimes contra a pessoa. Diário Oficial, Brasília, DF, 7 dez. 1940.

BRITO, Bruna \& SILVEIRA, Luana da. Entre nós e redes: experiências de formaçãointervenção para a saúde mental e atenção psicossocial. In: COSTA, Rosane; MACHADO, Barbara \& CURI, Paula (Orgs.). A Psicologia em extensão: corpos à margem, desafio à formação. Rio de Janeiro: Gramma,. p.133-56, 2018.

CONSELHO FEDERAL DE PSICOLOGIA. CFP defende descriminalização e legalização do aborto no Brasil. Disponível em: <https://site.cfp.org.br/cfp-defende-descriminalizacaolegalizacao-aborto-brasil/>. Acesso em: 28 nov 2018.

CONSELHO FEDERAL DE PSICOLOGIA. Manifesto de Bauru. Disponível em: $<$ https://site.cfp.org.br/wp-content/uploads/2017/05/manifesto-de-bauru.pdf >. Acesso em: 28 nov 2018.

CONSELHO FEDERAL DE ENFERMAGEM. Uma mulher morre a cada dois dias por aborto inseguro, diz Ministério da Justiça. Disponível em: <http://www.cofen.gov.br/uma-mulhermorre-a-cada-2-dias-por-causa-do-aborto-inseguro-diz-ministerio-da-saude_64714.html $>$.

Acesso em: 28 nov 2018. 
CONSELHO FEDERAL DE PSICOLOGIA. Legislação. Resoluções. Disponível em: $<$ https://site.cfp.org.br/wp-content/uploads/2012/07/codigo-de-etica-psicologia.pdf>.

CURI, Paula \& GAMA, Thais. Em pauta na formação em Psicologia: a criminalização do aborto e a violência de direitos. In: COSTA, Rosane; MACHADO, Barbara \& CURI, Paula. (Orgs). A Psicologia em extensão: corpos à margem, desafio à formação. Rio de Janeiro: Gramma Editora, 2018. 195-226.

CUSTÓDIO, A. V. L. Da solidão aos agenciamentos possíveis: as aventuras de uma acompanhante terapêutica. 2017. 80f. Trabalho de conclusão de curso - Departamento de Psicologia, Universidade Federal Fluminense, Campos dos Goytacazes (2017).

DINIZ, Diniz, MEDEIROS, Marcelo \& MADEIRO, Alberto. Pesquisa Nacional de Aborto 2016. Ciência e Saúde Coletiva. v.22, n.2, p. 653-60, 2017.

DINIZ, Debora. Aborto e saúde pública no Brasil. Cadernos de Saúde Pública. v.23, n.9, p.1992, 2007.

FOUCAULT, Michel. Vigiar e punir: nascimento da prisão. Raquel Ramalhete. Petrópolis: Editora Vozes, 2014.

HILÁRIO, Leomir. Da biopolítica à necropolítica: variações foucaultianas na periferia do capitalismo. Sapere aude. v.7, n.12, p. 194-210, 2016.

INSTITUTO PACS. Racismo, criminalização do aborto e violência obstétrica são as principais ameaças à saúde das mulheres na Zona Oeste do Rio. Disponível em: $<$ http://pacs.org.br/2015/06/03/racismo-criminalizacao-do-aborto-e-violencia-obstetrica-saoas-principais-ameacas-a-saude-das-mulheres-na-zona-oeste-do-rio/> Acesso em: 24 abr 2019.

NAÇÕES UNIDAS NO BRASIL. OMS: proibição não reduz número de abortos e aumenta procedimentos inseguros. Disponível em: <https://nacoesunidas.org/oms-proibicao-nao-reduznumero-de-abortos-e-aumenta-procedimentos-inseguros/>. Acesso em: 31 mar 2019.

NOVELINO, Aida. Maternidade: um perfil idealizado. Cad. Pesq. N.65, p. 21-9. mai 1988.

PALOMBINI, Analice. Acompanhamento terapêutico: dispositivo clínico-político. Psychê, v.10, n.18, p.115-27, set 2006.

PASSOS, Eduardo \& BARROS, Regina. A Construção do Plano da Clínica e o Conceito de Transdisciplinaridade. Psic.: Teor. e Pesq., v.16, n.1, p.71-79, jan/abr 2000.

PASSOS, Rachel. "Holocausto ou Navio Negreiro?": inquietações para a Reforma Psiquiátrica brasileira. Argumentum, v.10, n.3, p.10-22, dez 2018.

ZANARDO, Gabriela, URIBE, Magaly, NADAL, Ana \& HABIGZANG, Luísa. Violência Obstétrica no Brasil: uma revisão narrativa. Psicologia \& Sociedade. v.29, n.1, p.1-11, jul 2017. 